\title{
INFORMES PRECEPTIVOS DE LAS COMUNIDADES AUTÓNOMAS EN EL PROCEDIMIENTO LEGISLATIVO ESTATAL. COMENTARIO A LA STC 155/2017, DE 21 DE DICIEMBRE
}

\author{
Mandatory reports of the Autonomous Communities \\ in the State legislative procedure. Commentary \\ on the Judgement of the Constitutional Court of Spain \\ 155/2017, December 21
}

\author{
ÁNGEL MARRERO GARCÍA-ROJO \\ Parlamento de Andalucía \\ a.marrero@parlamento-and.es \\ Cómo citar/Citation \\ Marrero García-Rojo, Á. (2019). \\ Informes preceptivos de las comunidades autónomas en el procedimiento \\ legislativo estatal (comentario a la STC155/2017, de 21 de diciembre). \\ Revista Española de Derecho Constitucional, 115, 331-361 \\ doi: https://doi.org/10.18042/cepc/redc.115.11
}

\section{Resumen}

En el presente trabajo se comenta la STC 155/2017, que ha desestimado un recurso de inconstitucionalidad interpuesto contra una ley estatal, a pesar de que en su tramitación no se había emitido el preceptivo informe autonómico exigido por el Estatuto de Autonomía de Aragón. Se examina la naturaleza de los informes preceptivos de las comunidades autónomas en el procedimiento legislativo estatal y el régimen jurídico de aplicación, y se destaca la importancia del establecimiento de unas reglas precisas de procedimiento para la emisión del informe. Asimismo, se examinan las consecuencias de la omisión del informe autonómico preceptivo en función de los distintos supuestos y circunstancias que pueden concurrir. 


\title{
Palabras clave
}

Vicios del procedimiento legislativo; informe autonómico preceptivo; principio de cooperación entre Estado y comunidades autónomas.

\begin{abstract}
This paper comments the Judgement 155/2017, in which the Constitutional Court of Spain rejects an appeal of unconstitutionally lodged against a State law, despite the fact that the Autonomous Community had not issued during its proceedings the mandatory report required by the Autonomy Statute of Aragon. The paper examines the nature and the legal regime applicable to the mandatory reports by the Autonomous Communities in the State legislative procedure, emphasizing the importance of proper procedure rules to issue the report. It also examines the consequences of an omission of the mandatory report by the Autonomous Community with respect to the possible different situations an circumstances.
\end{abstract}

\section{Keywords}

Legislative procedural flaws, mandatory report of the Autonomous Community; principle of cooperation between State and Autonomous Communities. 


\section{SUMARIO}

I. INTRODUCCIÓN. II. ANTECEDENTES DE LA STC 155/2017. III. CONSECUENCIAS DE LA OMISIÓN DEL INFORME AUTONÓMICO PRECEPTIVO. IV. LA REGULACIÓN DEL INFORME AUTONÓMICO PRECEPTIVO. V. MOMENTO DE LA SOLICITUD Y EMISIÓN DEL INFORME AUTONÓMICO PRECEPTIVO. VI. LA EMISIÓN DEL INFORME AUTONÓMICO PRECEPTIVO EN LA STC 155/2017. VII. POSICIÓN QUE SE MANTIENE. BIBLIOGRAFÍA.

\section{INTRODUCCIÓN}

El art. 72.3 del Estatuto de Autonomía de Aragón ${ }^{1}$ establece que «[...] para la defensa de los derechos relacionados con el agua contemplados en el artículo 19, la Comunidad Autónoma emitirá un informe preceptivo para cualquier propuesta de obra hidráulica o de transferencia de aguas que afecte a su territorio. El Gobierno de España deberá propiciar de forma efectiva el acuerdo entre todas las Comunidades Autónomas que puedan resultar afectadas».

El precepto estatutario ha sido ya importante protagonista de varias sentencias del Tribunal Constitucional. Así, en primer término, fue objeto directo del recurso de inconstitucionalidad interpuesto por el Consejo de Gobierno de la comunidad autónoma de La Rioja y resuelto por la STC 110/2011, de 22 de junio, que desestimó su impugnación (FF.JJ. 14 y 15).

Posteriormente, la STC 13/2015, de 5 de febrero, va a declarar la inconstitucionalidad y nulidad de la disposición adicional decimoquinta; la disposición transitoria segunda; la disposición derogatoria única, apartado tercero, y las disposiciones finales segunda y tercera de la Ley 21/2013, de 9 de diciembre, de evaluación ambiental, precisamente por haberse aprobado con omisión del preceptivo informe previsto en el art. 72.3 del Estatuto de Autonomía de Aragón (FJ 5). Sin embargo, y por las razones que se exponen en ese fundamento jurídico, la nulidad derivada de la declaración de inconstitucionalidad de esos preceptos se difiere por el plazo de un año, a partir de la publicación de la sentencia, que tuvo lugar en el Boletín Oficial del Estado el día 2 de marzo de 2015.

Finalmente, la STC 155/2017, de 21 de diciembre, desestima el recurso de inconstitucionalidad interpuesto por el Gobierno de la comunidad autónoma

$1 \quad$ Ley Orgánica 5/2007, de 20 de abril. 
de Aragón contra la disposición adicional quinta; la disposición transitoria única; la disposición derogatoria única, y las disposiciones finales primera y segunda de la Ley 21/2015, de 20 de julio, por la que se modifica la Ley 43/2003, de 21 de noviembre, de Montes. El recurso se fundaba, entre otros motivos, en que no se había emitido, en relación con esos preceptos, el informe previsto en el art. 72.3 del Estatuto de Autonomía de Aragón.

\section{ANTECEDENTES DE LA STC 155/2017}

Como se ha expuesto, la STC 13/2015 declaró la inconstitucionalidad y nulidad diferida de diversas disposiciones de la Ley 21/2013, de 9 de diciembre, de evaluación ambiental, al haberse omitido el informe preceptivo previsto en el art. 72.3 del Estatuto de Autonomía de Aragón.

Posteriormente, durante la tramitación parlamentaria de la Ley 21/2015, de 20 de julio, por la que se modifica la Ley 43/2003, de 21 de noviembre, de Montes, el Grupo Parlamentario Popular presentó en el Congreso de los Diputados diversas enmiendas de adición cuyo contenido coincidía con el de las disposiciones que habían sido declaradas inconstitucionales por la STC $13 / 2015$ y que se encontraban todavía vigentes por no haber transcurrido el plazo para que se produjera su nulidad diferida. El contenido de dichas enmiendas sería finalmente aprobado como parte integrante de la Ley 21/2015, constituyendo en concreto las disposiciones que fueron objeto del recurso de inconstitucionalidad resuelto por la STC 155/2017, que ahora específicamente comentamos.

En esencia, el Gobierno de la comunidad autónoma de Aragón fundamenta su recurso de inconstitucionalidad contra las señaladas disposiciones de la Ley 21/2015 en dos órdenes de consideraciones. En primer lugar, en la circunstancia de que las disposiciones recurridas tienen su origen en las enmiendas de adición que se presentaron en el Congreso de los Diputados, enmiendas que no guardarían la necesaria relación de homogeneidad o conexión material con el contenido del proyecto de ley presentado. En segundo lugar, porque, otra vez, se habría incumplido el art. 72.3 del Estatuto de Autonomía de Aragón, al no haberse emitido el informe preceptivo que allí se prevé.

Respecto de la primera cuestión, la ausencia de homogeneidad o conexión material entre las enmiendas y el proyecto de ley, el Tribunal Constitucional va a rechazar los argumentos del recurrente al considerar (FJ 3c) que «lo determinante es que la conversión de aquellas enmiendas en preceptos de ley no alter[ó] de manera sustancial el proceso de formación de la voluntad en el seno de las Cámaras legislativas». Razona en este sentido que las disposiciones 
impugnadas carecieron de todo alcance innovador sustantivo, al ser mera reiteración de otras ya aprobadas por las propias Cortes Generales en esa misma legislatura ${ }^{2}$.

En cuanto a la segunda cuestión, la relativa al informe preceptivo del art. 72.3 del Estatuto de Autonomía de Aragón, que es la que aquí específicamente nos va a interesar, conviene exponer las esenciales circunstancias relevantes al efecto que se desprenden de los antecedentes y fundamentos jurídicos de la STC 155/2017²:

a) Las enmiendas de adición cuyo contenido coincide con el de las disposiciones de la Ley 21/2015 recurridas ${ }^{4}$ fueron presentadas el día 28 de abril de 2015, dirigidas a la Mesa de la Comisión de Agricultura, Alimentación y Medio Ambiente del Congreso de los Diputados. El día 8 de mayo de 2015 la ponencia acordó tanto su aceptación como solicitar el informe previsto en el art. 72.3 del Estatuto de Autonomía de Aragón. El día 12 de mayo el presidente del Congreso de los Diputados dirigió oficio a la Presidencia de la comunidad autónoma de Aragón interesando la emisión del informe, oficio que fue recibido el día 19 de mayo. Entretanto, el día 13 de mayo la Comisión de Agricultura, Alimentación y Medio Ambiente aprobó, con competencia

2 La argumentación del Tribunal plantea dudas. En primer lugar, porque parece partir de la idea de que, expresada la voluntad parlamentaria en una legislatura, hay que suponer que dicha voluntad se va a mantener durante esta. Sin embargo, la suposición parece excesiva, aunque solo sea porque son numerosísimos los casos en que una Asamblea Legislativa cambia su parecer normativo en una misma legislatura. Pero, en segundo lugar, y sobre todo, el Tribunal olvida que esa voluntad parlamentaria previamente expresada había sido declarada inconstitucional y nula en su STC 13/2015 precisamente porque se estimó que adolecía de un vicio, la ausencia del preceptivo informe del art. 72.3 del Estatuto de Autonomía de Aragón, que afectaba a su correcta formación, de manera que, de haberse emitido el informe, otra podría haber sido la voluntad parlamentaria producida previamente.

3 Pueden examinarse también los documentos que se recogen en la Revista de las Cortes Generales, núms. 100-101-102 (cuatrimestres primero, segundo y tercero de 2017), pp. 569 y ss.

4 Resulta curioso que, según se expone en los antecedentes de la sentencia, el recurrente consideraba que la disposición final segunda de la Ley 21/2015 no se encontraba afectada por lo previsto en el art. 72.3 del Estatuto de Autonomía de Aragón. Sin embargo, dicha disposición coincide en su contenido con el de la disposición final tercera de la Ley 21/2013, que fue declarada inconstitucional por la STC $13 / 2015$ precisamente por incumplimiento del considerado precepto estatutario. 
legislativa plena, el proyecto de ley, con la incorporación de las consideradas enmiendas.

En el Senado, se presentaron diversas enmiendas para la supresión del contenido de las que habían sido aprobadas en el Congreso de los Diputados y que ahora nos interesan, justificadas todas ellas en la ausencia del informe previsto en el art. 72.3 del Estatuto de Autonomía de Aragón y con referencia a la STC 13/2015. La ponencia rechazó tales enmiendas; la Comisión de Medio Ambiente y Cambio Climático aprobó el informe de la ponencia, y, por último, el día 25 de junio de 2015, el Pleno del Senado rechazó los votos particulares de los senadores que habían propuesto la supresión del contenido de las enmiendas que nos ocupan.

Finalmente, el Pleno del Congreso de los Diputados aprobó el proyecto de ley el día 8 de julio de 2015.

b) Por otra parte, en el fundamento jurídico 6b de la STC 155/2017 se señala que las enmiendas consideradas fueron sin duda conocidas por las instituciones autonómicas, dados los términos de la solicitud de comparecencia de la presidenta del Gobierno autonómico que se admitió a trámite el día 4 de mayo por la Mesa de la Diputación Permanente y la Junta de Portavoces de las Cortes de Aragón (entonces disueltas) y el contenido del subsiguiente debate, que tuvo lugar el día 7 de mayo en la Diputación Permanente.

Pues bien, la STC 155/2017 desestima el recurso de inconstitucionalidad, argumentando, en esencia (FJ 8), que la comunidad autónoma de Aragón pudo haber emitido el informe previsto en el art. 72.3 del Estatuto de Autonomía de Aragón o, en su defecto, pudo hacer valer la considerada atribución estatutaria ante las Cortes Generales, formulando la correspondiente solicitud o protesta al efecto, lo que no hizo.

La Sentencia cuenta con un voto particular, del magistrado Conde-Pumpido Tourón, que considera que el recurso de inconstitucionalidad debió ser estimado como consecuencia, precisamente, de la omisión del informe preceptivo que prevé el art. 72.3 del Estatuto de Autonomía de Aragón.

\section{CONSECUENCIAS DE LA OMISIÓN DEL INFORME AUTONÓMICO PRECEPTIVO}

La constitucionalidad del informe preceptivo previsto en el art. 72.3 del Estatuto de Autonomía de Aragón fue confirmada por la STC 110/2011, 
según expusimos con anterioridad, sin que vaya a ser objeto de este comentario la corrección de tal solución 5 .

Tampoco será aquí objeto de consideración la posibilidad de exigir tales informes en la tramitación de los procedimientos legislativos estatales. La cuestión fue resuelta por la STC 13/2015 en su fundamento jurídico 5d, al contestar las alegaciones del Congreso de los Diputados en el sentido de que la emisión de estos informes debe entenderse referida a las decisiones de naturaleza ejecutiva o prelegislativa. Responde el Tribunal Constitucional, en efecto, que tales razones no resultan asumibles, pues supondría tanto como admitir que las Cámaras no quedan concernidas por una norma que ellas mismas han aprobado con el rango de ley orgánica y que, en su condición de norma institucional básica de la comunidad autónoma, integra el bloque de la constitucionalidad. Ańade que, al tratarse de un informe preceptivo y no vinculante, no puede entenderse tampoco que entorpezca el procedimiento legislativo o afecte a la autonomía parlamentaria, en la medida en que, por el contrario, puede servir para proporcionar a la Cámara una información adicional a tener en cuenta durante la tramitación legislativa ${ }^{6}$.

5 Sobre la constitucionalidad de dicho informe existió polémica doctrinal, expresada en términos bastante rotundos a veces, por cierto. A favor de la constitucionalidad, Embid Irujo (2007: 31 y ss. y 69 y ss.; 2009: 46 y ss. y 57-58) y Bassols Coma (2008: 390-391); en contra, Fanlo Loras (2007: 342-346) y Garrorena Morales, este último en obra conjunta con Fanlo (2008: 69 y ss.). En general, sobre estas cuestiones, recientemente, Castro Marquina (2016: 86 y ss.).

6 Aunque, como hemos expuesto, el análisis de esta cuestión excede del objeto de este comentario, y conscientes de los riesgos que siempre presenta la interpretación a sensu contrario, no podemos dejar de destacar que las declaraciones del Tribunal Constitucional podrían interpretarse en el sentido de que estos informes solo pueden venir previstos en la Constitución o en los estatutos de autonomía o, a lo más, en otras normas integrantes del bloque de la constitucionalidad. Sin embargo, y sin perjuicio de la evidente peculiaridad y las consecuencias que se derivarían de la circunstancia de que el informe estuviera previsto en una ley ordinaria estatal, que no es susceptible de condicionar el procedimiento de aprobación de otra ley estatal de las mismas características, creemos que la cuestión puede ofrecer muchas dudas cuando el informe preceptivo está previsto en una ley orgánica o, especialmente, en una ley autonómica. Claro está que todas estas cuestiones guardan íntima relación con el escurridizo concepto del bloque de la constitucionalidad, o con cuestiones afines, tales como las relativas a los parámetros de constitucionalidad de las leyes o a la denominada inconstitucionalidad mediata o indirecta. En realidad, si se ha admitido por el Tribunal Constitucional que la ley autonómica pueda sujetar a un informe preceptivo autonómico el ejercicio de determinadas competencias estatales (vide STC 
Sin embargo, sí creemos conveniente realizar una serie de consideraciones sobre una cuestión que no ha sido tratada frontalmente por la STC 155/2017, cual es la relativa a los efectos que sobre las disposiciones legales recurridas produciría la circunstancia de que, en efecto, el preceptivo informe autonómico hubiera sido omitido de manera irregular?. Se trata de determinar si, en ese supuesto, siempre se produciría la inconstitucionalidad y nulidad de las correspondientes disposiciones legales, cuestión a la que tampoco aludió, por cierto, la STC 13/2015, es de suponer que porque no le ofrecía ninguna duda que así ha de ocurrir.

Ciertamente, hasta el momento el Tribunal Constitucional ha considerado que la irregular omisión de los informes preceptivos autonómicos previstos en la Constitución y en normas integrantes del bloque de la constitucionalidad y, en concreto, en los estatutos de autonomía supone la inconstitucionalidad y nulidad de la correspondiente ley. Así ha ocurrido en relación con el informe o la audiencia de la comunidad autónoma de Canarias a que se refieren la disposición adicional tercera de la Constitución y el actual art. 46 del Estatuto de Autonomía de Canarias, supuestos que guardan esencial similitud con el que específicamente nos ocupa en este comentario, tal y como reconoce expresamente la STC 13/2015 (FJ 5d). En efecto, desde la muy temprana STC 35/1984, de 13 de marzo, se ha venido sosteniendo, sin fisuras ni cuestionamientos, tal solución ${ }^{8}$.

A nuestro juicio, la propia aplicación de la doctrina general del Tribunal Constitucional sobre los vicios en el procedimiento legislativo' ${ }^{9}$ conduce a

46/2007, de 1 de marzo, FJ 10), parece que ello debe extenderse al supuesto en que ese ejercicio de las competencias estatales tiene lugar a través de la ley, máxime cuando, como es conocido, nuestro sistema no contempla la denominada reserva reglamentaria. En cualquier caso, sobre estas cuestiones siguen siendo imprescindibles las ponencias y discusiones contenidas en Favoreu y Rubio Llorente (1991).

7 Es sumamente importante para la adecuada comprensión de lo que exponemos en este comentario que quede perfectamente claro desde este mismo momento que cuando nos refiramos en él a irregular omisión del informe autonómico preceptivo, o utilicemos una expresión semejante, estaremos aludiendo a aquellos casos en que, efectivamente, la correspondiente disposición legal no debió, jurídicamente, ser aprobada, como consecuencia de que no se había emitido el informe. Para mayor claridad de lo que exponemos, queremos decir que quedan fuera de las consideradas expresiones supuestos tales como la jurídicamente correcta aprobación, en su caso, de la disposición legal, a pesar de que no se había emitido el informe, porque había transcurrido el plazo establecido para emitirlo o porque había existido una falta de diligencia relevante en su emisión.

8 No obstante, la radical conclusión del Tribunal Constitucional fue cuestionada por el recordado magistrado Arozamena Sierra en su voto particular.

9 Sobre estas cuestiones sigue siendo imprescindible Biglino Campos (1991). 
negar que la omisión irregular del informe preceptivo autonómico tenga que determinar siempre y en todo caso la inconstitucionalidad y nulidad de la disposición impugnada. En efecto, reiteradamente ha declarado el Tribunal Constitucional (por todas, STC 176/2011, de 8 de noviembre, FJ 4) que

[...] la inobservancia de los preceptos que regulan el procedimiento legislativo podría viciar de inconstitucionalidad la ley cuando esa inobservancia altere de modo sustancial el proceso de formación de voluntad en el seno de las Cámaras [...] siendo necesario a tales efectos que el vicio o inobservancia denunciada afecte «esencialmente al proceso de formación de la voluntad de los parlamentarios, de modo que sólo los vicios o defectos más graves provocan un déficit democrático en el proceso de elaboración de una norma que podría conducir a su declaración de inconstitucionalidad».

De este modo, conforme a esa doctrina general ${ }^{10}$, si efectivamente la irregular omisión del informe autonómico no ha alterado de modo sustancial o no ha afectado esencialmente al proceso de formación de la voluntad parlamentaria, parece claro que tal irregular omisión no tendría efecto invalidante de la disposición impugnada. Ahora bien, lógicamente, se plantean al respecto dos cuestiones fundamentales. Primero, cuándo se ha producido esa alteración o afectación sustancial o esencial. Segundo, el que podríamos denominar reparto de la carga de la prueba, esto es, si es preciso que quien reclama la inconstitucionalidad de la disposición acredite esa alteración o afectación sustancial o esencial o, por el contrario, si lo que debe acreditarse, por quien lo sostenga, para evitar la declaración de inconstitucionalidad, es que aquellas no se han producido.

En este sentido, si se tiene en cuenta que, como ha declarado el Tribunal Constitucional (por todas, STC 136/2011, de 13 de septiembre, FJ 6), en el ejercicio de la autonomía reglamentaria que la Constitución reserva a las Cámaras (art. 72 de la Constitución) les corresponde una función ordenadora de la vida interna de las Asambleas, parece claro que la exigencia externa de un determinado informe, que constituye excepción a la regla general de autonormación parlamentaria, tiene que venir avalada por poderosas razones. Con ello queremos seńalar que cuando se exige, al margen de los reglamentos y normas parlamentarios, un informe en el procedimiento para la aprobación de la ley es porque se considera que dicho informe tiene una

10 A la que, por cierto, alude también la STC 155/2017, en sus fundamentos jurídicos 2 y 3 , refiriéndola a todos los supuestos de inobservancia de los preceptos que regulan el procedimiento legislativo o a cualesquiera vicios de procedimiento. 
esencial y sustancial relevancia para la adecuada formación de la voluntad de las Cámaras. Y, por eso, y he aquí la conclusión que ahora queríamos alcanzar, consideramos que la regla de la que debe partirse es que la irregular omisión del informe preceptivo es susceptible de producir una sustancial alteración en el proceso de formación de la voluntad de los parlamentarios y, en consecuencia, en principio, determinará la inconstitucionalidad y nulidad de la correspondiente disposición ${ }^{11}$.

De este modo, quien sostenga en el correspondiente proceso constitucional que la irregular omisión del informe preceptivo no ha determinado una sustancial o esencial alteración del proceso de formación de la voluntad parlamentaria deberá acreditarlo así. Y, naturalmente, tratándose de una ley, esa prueba va a resultar especialmente complicada, supuestos su importante carácter político y los amplios niveles de libertad de configuración que ostenta el legislador (por todas, STC 191/2016, de 15 de noviembre, FJ 3).

\section{LA REGULACIÓN DEL INFORME AUTONÓMICO PRECEPTIVO}

Ya hemos señalado que la previsión de un informe preceptivo autonómico en procedimientos estatales puede venir recogida en una norma indudablemente integrante del bloque de la constitucionalidad, como señaladamente son los estatutos de autonomía, pero también en otras leyes orgánicas, en una ley ordinaria estatal o en una ley autonómica. Naturalmente, el respeto a la autonomía de organización de la comunidad autónoma determina que la fijación del concreto órgano autonómico que haya de emitir ese informe corresponda a la normativa autonómica ${ }^{12}$. Y lo mismo cabe seña-

11 No puede dejar de llamarse la atención sobre que la STC 68/2013, de 14 de marzo (FJ 3), se refiere al rango de la norma que prevea el informe como elemento determinante para provocar la inconstitucionalidad de la disposición legal, con cita de la STC 35/1984. La afirmación parece poco pensada o matizada, máxime cuando se formula en un ámbito específico distinto, en relación con el art. 88 de la Constitución.

12 Así lo señala la STC 155/2017 (FJ 5a), al aludir a la reserva de dejar siempre a salvo la exclusiva competencia de la comunidad autónoma en punto a la ordenación de sus instituciones de autogobierno. Claro está que, en su caso, tal previsión puede recogerse también en el propio estatuto de autonomía (como ocurre con el informe de la comunidad autónoma de Canarias al que se refiere la disposición adicional tercera de la Constitución). 
lar respecto de otros aspectos que se mantengan en la estricta esfera interna autonómica, esto es, esencialmente, en lo relativo al procedimiento interno de elaboración del informe (propuestas, plazos internos para la realización de las correspondientes actuaciones encaminadas a la elaboración y aprobación del informe, etc.).

Ahora bien, el Tribunal Constitucional se ha preocupado de dejar sentado que, tratándose de informes autonómicos que se insertan en procedimientos estatales, la competencia para la regulación del modo de inserción del informe en el procedimiento estatal corresponde precisamente al Estado. Así, en el fundamento jurídico 5a de la STC 155/2017, tras recordar que, respecto del art. 72.3 del Estatuto de Autonomía de Aragón, la STC 13/2015 ya se había referido (FJ 5d) a la «eventual norma estatal que regulase tal procedimiento», señala que «[c]ómo y cuándo se articule en el curso de los procedimientos estatales la atribución autonómica que consideramos ahora son aspectos, en definitiva, cuya determinación corresponde al Estado, sin perjuicio de que se ha de asegurar que tal participación sea efectiva».

Por lo demás, cuando el informe se ha de producir en el desarrollo de un procedimiento legislativo estatal, que es el supuesto que aquí específicamente nos interesa, no puede dejar de recordarse la ya expuesta doctrina del Tribunal Constitucional en el sentido de que en el ejercicio de la autonomía reglamentaria que la Constitución reserva a las Cámaras les corresponde una función ordenadora de la vida interna de las Asambleas, para regular su propia organización y funcionamiento, así como para articular las fases o procedimientos que se desarrollan en su seno. De esta forma, son los reglamentos parlamentarios ${ }^{13}$ los que, en principio, deben contener esa regulación del informe ${ }^{14}$.

Solo en supuestos muy excepcionales puede pensarse en la posibilidad de que la ley estatal determine el concreto órgano autonómico que haya de emitir el informe. Así, por ejemplo, no hay que excluir la concurrencia de circunstancias que puedan justificar que se exija que ese informe lo emita el correspondiente Parlamento autonómico, pero, recalcamos, la afectación a la autonomía de organización de la comunidad autónoma que en tales casos se produciría determina que la exigencia tenga que venir apoyada en muy poderosas razones.

13 O, eventualmente, aquellas normas que pueden aprobar las Cámaras, según su específica ordenación, para suplir las lagunas u omisiones de los reglamentos parlamentarios.

14 Ciertamente, no sería posible descartar, ni considerar siempre inconstitucional, que las leyes, de una u otra naturaleza, incluso las autonómicas, que previeran el informe 
En cualquier caso, para lo que no parece que hagan falta demasiadas consideraciones es para destacar que para quien ha de emitir el informe la existencia de un procedimiento adecuadamente articulado en el que queden definidos con precisión sus aspectos esenciales (y, desde luego, sobresalen en este sentido la determinación de cuándo se ha de solicitar el informe y cuál es el régimen temporal para su emisión) es sumamente relevante, en cuanto que dota de certidumbre y seguridad jurídica a su actuación.

\section{MOMENTO DE LA SOLICITUD Y EMISIÓN DEL INFORME AUTONÓMICO PRECEPTIVO}

Cuestión sin duda de la máxima relevancia en todos aquellos supuestos en los que se prevé la existencia de un informe preceptivo en la tramitación de cualquier procedimiento es la determinación de los momentos concretos en que aquel ha de ser solicitado y emitido.

Parece claro que, ante todo, hay que estar al respecto a lo que establezca la norma que ha previsto el informe y la caracterización con la que haya dotado a este. Asimismo, sobre esta base inicial, es evidente que serán las normas estatales, parlamentarias en supuestos como el que nos ocupa, llamadas a regular el modo de inserción del informe en el procedimiento estatal, a cuya relevancia ya nos hemos referido en el apartado IV de este comentario, las que deberán establecer, en aras de la seguridad jurídica, previsiones precisas y específicas sobre tan importantes circunstancias ${ }^{15}$.

Ahora bien, en el supuesto resuelto por la STC 155/2017 no existía, más allá de la propia previsión del art. 72.3 del Estatuto de Autonomía de Aragón,

preceptivo pudieran, a su vez, establecer determinadas normas procedimentales al efecto. Pero, sin duda, supuesta esa preferencia del reglamento o norma parlamentarios a que hemos aludido, deben ser poderosísimas razones, normalmente ligadas a la especificidad del sector, materia o aspecto que se está regulando, las que legitimen la excepción.

Sobre estas cuestiones, Jiménez Asensio (1996) y Pascua Mateo (2014: 122 y ss.).

15 Lo que, en definitiva, queremos expresar es que la determinación del momento concreto en el que ha de solicitarse y emitirse el informe preceptivo exige, ante todo, una interpretación del precepto que inicialmente ha previsto el informe. Ahora bien, debe quedar claro que es perfectamente posible que, tras esa interpretación, se llegue a la conclusión, por unas u otras razones, de que la cuestión no ha quedado resuelta definitivamente por ese precepto y que la normativa que vaya a regular con posterioridad ese informe tiene abierta una pluralidad de posibilidades, todas legítimas, al respecto. 
ninguna norma parlamentaria que estableciera previsiones procedimentales específicas respecto del informe previsto en el considerado precepto estatutario. Por ello, es de interés destacar los pronunciamientos que hasta ahora ha realizado el Tribunal Constitucional en supuestos análogos, esto es, en los que tampoco existía una específica regulación procedimental del momento de solicitud y emisión del correspondiente informe. Los mismos se han producido prácticamente en su totalidad con ocasión de procesos constitucionales en los que se suscitaban problemas atinentes al informe preceptivo previsto en la disposición adicional tercera de la Constitución y en el art. 46.3 del Estatuto de Autonomía de Canarias ${ }^{16}$.

En este momento, puede señalarse que la regla general en la doctrina del Tribunal Constitucional, sentada en la STC 16/2003, de 30 de enero, fundamento jurídico 9, es que la emisión del preceptivo informe «ha de producirse sobre el texto propio de la iniciativa legislativa, es decir, antes de la tramitación en las Cortes Generales». Por tanto, a pesar de que tanto la Constitución como el Estatuto de Autonomía de Canarias tan solo exigen el informe preceptivo para la modificación ${ }^{17}$ del régimen económico y fiscal canario, el Tribunal Constitucional impone que si el proyecto de ley aprobado por el Gobierno contiene algún precepto que, de ser aprobado definitivamente, implique esa modificación, deberá producirse sobre aquel el preceptivo informe del Parlamento autonómico «antes de la tramitación en las Cortes Generales ${ }^{18}{ }^{\prime}$.

A continuación, no obstante, el Tribunal Constitucional va a prever el supuesto de que durante la tramitación en las Cortes Generales se introduzcan, respecto del proyecto de ley, modificaciones que, señala, en el caso de que lo alteren tan radicalmente que no pueda tenerse por informado, exigirán

16 En cualquier caso, a los efectos que en este comentario nos van a interesar, es irrelevante la diferencia entre el informe y la audiencia que prevén, respectivamente, el apdo. 3 y el apdo. 4 del art. 46 del Estatuto de Autonomía de Canarias.

17 Esto es, de la literalidad de los preceptos constitucional y estatutario tan solo se desprende que si se ha aprobado definitivamente la modificación del régimen económico y fiscal canario se ha debido emitir previamente el informe preceptivo del Parlamento de Canarias.

18 Parece bastante claro que el Tribunal Constitucional está pensando, cuando hace esa declaración, exclusivamente en el supuesto de que la iniciativa legislativa haya sido ejercida por el Gobierno mediante la presentación de un proyecto de ley, tal como ocurría en el proceso constitucional del que estaba conociendo. Las peculiaridades de las demás formas de iniciativa legislativa previstas en el art. 87 de la Constitución parece que hubieran determinado, si no estuviéramos en lo cierto, alguna referencia específica. 
nuevo informe del Parlamento canario ${ }^{19}$. En estos casos, por tanto, es evidente que el informe habrá de solicitarse y emitirse durante la tramitación ante las Cortes Generales, lo que lo conecta directamente con el objeto de nuestro comentario.

Continuando con el examen de los pronunciamientos del Tribunal Constitucional sobre el momento de solicitud y emisión del informe, nos referimos ahora a un supuesto muy específico, cual es el de que la modificación del régimen económico y fiscal canario se haya llevado a cabo mediante real decreto ley. El Tribunal Constitucional se pronunció al respecto tempranamente en la STC 35/1984, de 13 de marzo, fundamento jurídico 4, afirmando que el informe preceptivo autonómico puede obtenerse antes de la convalidación del real decreto ley ${ }^{20}$.

19 La posibilidad de introducir esas modificaciones radicales sobre el proyecto de ley, que el Tribunal Constitucional llega a calificar de obvia, no es hoy, desde luego, tan clara con la doctrina que se inició con las SSTC 119/2011, de 5 de julio, y 136/2011, de 13 de septiembre, en relación con las enmiendas en los procedimientos legislativos. En efecto, aun cuando la cuestión sigue ofreciendo dudas y confusiones tanto en la doctrina del Tribunal Constitucional como en la doctrina científica, parece que debe exigirse a las enmiendas no solo que resulten homogéneas o que guarden conexión material con el contenido del proyecto de ley, sino también que resulten congruentes, esto es, que respondan a su objeto, espíritu y fines esenciales. Y, desde luego, el supuesto que plantea la STC 16/2003 de alteraciones tan radicales en el proyecto de ley que justifiquen un nuevo informe del Parlamento autonómico parece que puede entrar en colisión con esa exigencia de congruencia.

El Tribunal Constitucional reconocía expresamente que esa alteración radical no se daba en el caso que estaba resolviendo. Y, precisamente, ello es lo que motiva el voto particular concurrente que formularon hasta seis magistrados, que consideraban que, por tal razón, las apuntadas afirmaciones no deberían haber sido incluidas en el texto de la sentencia y, en todo caso, no tenían otro valor ni alcance que el atribuible a un puro o simple obiter dictum. El voto particular ha adquirido relevancia práctica porque en sentencias posteriores se han reproducido tales afirmaciones del Tribunal Constitucional, viniendo a considerarlas como doctrina de este.

20 De este modo, parece que se deja libertad para que el informe sea solicitado por el Gobierno antes de la aprobación del real decreto ley o por el Congreso de los Diputados antes de su convalidación. En general, la doctrina ha criticado tal posibilidad: Martín Cáceres (1988: 466) o Mauricio Subirana (1994: 236 y ss.), que se refiere también a pronunciamientos del Consejo Consultivo de Canarias en tal sentido. Una postura más matizada, en Orozco Muñoz (1997: 339 y ss.). En general, sobre todas las cuestiones relativas al informe y audiencia previstos en la disposición adicional tercera de la Constitución y en el art. 46 del Estatuto de Autonomía de Canarias, pueden consultarse Moreno Fernández (2018) y la bibliografía que cita. 
Hasta aquí los pronunciamientos expresos del Tribunal Constitucional sobre el momento de la solicitud o de la emisión del informe preceptivo autonómico. Pues bien, partiendo de la posibilidad de que vía enmienda se introduzca por primera vez un precepto que, de ser aprobado, hubiera requerido el informe preceptivo autonómico, lo primero que hay que señalar es que hasta el momento el Tribunal Constitucional, por unas u otras razones, no se ha pronunciado expresamente sobre el momento concreto en que ha de solicitarse el informe en tales supuestos ${ }^{21}$.

En este sentido, la primera cuestión que se plantea es si presentada una enmienda con un contenido susceptible de determinar la necesaria emisión del informe autonómico, este debe solicitarse antes de su admisión a trámite o votación o, por el contrario, solo cuando se asume el contenido de la enmienda por algún órgano parlamentario surge la necesidad de solicitar el informe ${ }^{22}$.

A nuestro juicio, es posible una postura integradora de ambas posiciones. Ciertamente, creemos que es esencial respetar, en la medida de lo posible, la ordenación del procedimiento legislativo previsto, de manera que todos los órganos llamados a intervenir y en los momentos establecidos puedan contar, siempre que ello sea posible, teniendo en cuenta el momento de presentación de la enmienda, con el informe autonómico para adoptar su decisión de modo adecuado. Así parece, por lo demás, declararlo la STC 155/2017, al señalar en su fundamento jurídico 5 que «el órgano del Estado ha de [...] dar ocasión para que el criterio autonómico pueda ser manifestado y tenido en cuenta en cada fase procedimental relevante antes de que llegue a su término el procedimiento mismo». Pero, por otro lado, no son desdeñables las consideraciones de orden práctico (esencialmente, la demora en la tramitación parlamentaria, incluso en supuestos en los que la enmienda tiene muy pocas posibilidades de

21 Así, en los recursos de inconstitucionalidad resueltos por las SSTC 67/2005, de 17 de marzo, y 164/2013, o en las aquí específicamente consideradas SSTC 13/2015 y $155 / 2017$.

22 Esta última es la postura defendida por la representación del Congreso de los Diputados en el recurso de inconstitucionalidad resuelto por la STC 155/2017. En el antecedente $6 \mathrm{~b}$ de esta se recoge, en efecto, que en esa Cámara, siguiendo la práctica del caso canario, la solicitud de informe no se cursa con la simple presentación de la enmienda, sino cuando la misma es aprobada por los órganos de la Cámara, dado que no parece que tenga sentido solicitar el informe de modo tan prematuro, con la simple presentación de la enmienda, o a modo cautelar. Por el contrario, el recurrente pretendía que en la ponencia, primer órgano parlamentario que se pronuncia sobre la aceptación de la enmienda, ya debería disponerse del informe. En la práctica, en el supuesto que nos ocupa, la ponencia hizo constar en su informe tanto la aceptación de las enmiendas como su acuerdo de solicitar el preceptivo informe autonómico. 
prosperar) a que conduciría exigir el informe autonómico por el solo hecho de que se haya presentado una enmienda.

La solución que proponemos consistiría en someter previamente a votación del correspondiente órgano parlamentario si se rechaza la enmienda. En caso de que así se acuerde, proseguirá la tramitación parlamentaria sin necesidad de solicitar el informe autonómico ${ }^{23}$. En caso contrario, se procederá a solicitar el informe autonómico, con la consiguiente paralización del procedimiento que proceda hasta, en su caso, que el informe autonómico sea emitido y recibido ${ }^{24}$.

\section{LA EMISIÓN DEL INFORME AUTONÓMICO PRECEPTIVO EN LA STC 155/2017}

Como exponíamos más arriba, el Tribunal Constitucional considera que la irregular omisión del informe preceptivo autonómico determina, en todo

23 En su caso, hasta el momento en que otro órgano parlamentario tenga que pronunciarse sobre la aceptación de la enmienda, por mantenerse esta viva en terminología parlamentaria, en cuyo caso se procederá de modo análogo al anteriormente expuesto.

24 Ciertamente, el principal argumento que se puede oponer a esta solución es que se está permitiendo adoptar una decisión, aunque sea de rechazo, sobre el contenido de la enmienda sin el preceptivo informe autonómico. Sin embargo, a nuestro juicio, con carácter general el espíritu de los preceptos que exigen los informes autonómicos es el de que cualquier decisión que se adopte en sentido positivo, esto es, que altere la realidad existente, en relación con el ámbito material propio del precepto, debe contar con el correspondiente informe. Sin embargo, no necesariamente cualquier propuesta, provenga de quien provenga, justifica su emisión, sin que, desde luego, pueda equipararse a tal efecto la propuesta que constituye ejercicio de la iniciativa legislativa con supuestos como el que nos ocupa, enmiendas formuladas por quien corresponda en el procedimiento legislativo. Y ello incluso, en una adecuada interpretación, cuando el precepto que impone el informe alude, sin más, a propuesta, tal como ocurre con el art. 72.3 del Estatuto de Autonomía de Aragón.

Por lo demás, no puede dejar de recordarse que la solución que proponemos lo es para un supuesto en que no se ha procedido a la regulación parlamentaria, en los términos más arriba expuestos, del informe en cuestión. Con ello queremos reiterar la trascendencia de esa regulación, con la consiguiente seguridad jurídica. Es más, dicha regulación, sin duda, puede prever especialidades respecto de la tramitación habitual del procedimiento parlamentario, siempre que no se opongan a las exigencias reglamentarias, con la finalidad de adaptarse a las peculiaridades de los supuestos que nos ocupan (así, cabe pensar en que esas especialidades pueden afectar a aspectos o actuaciones que en los supuestos habituales están cubiertos por la costumbre o práctica parlamentarias). 
caso, la inconstitucionalidad y nulidad de la ley recurrida. Pero, dando un paso más, entiende que esa irregular omisión se produce siempre que, siendo precisa, no ha tenido lugar la solicitud del informe al órgano autonómico correspondiente. Así se desprende con toda claridad de diversos pasajes de la STC $155 / 2017^{25}$, en la que incluso se señala (FJ $7 \mathrm{~b}$ ) que «de ninguna manera es igual la responsabilidad constitucional que cabe esperar de quienes son directa y formalmente requeridos para evacuar un cierto informe que la que alguna vez se ha alegado ante nosotros sobre la sola base de que la Comunidad Autónoma hubiera podido conocer el procedimiento legislativo en curso por la propia publicidad de los trabajos parlamentarios ${ }^{26}{ }_{\text {». }}$

Como resulta con facilidad de las consideraciones que también más arriba exponíamos, no podemos tampoco compartir esta postura. En efecto, si aun cuando no se ha solicitado el informe queda acreditado, en los términos que seńalábamos, de una u otra manera, que no se ha alterado sustancialmente el proceso de formación de la voluntad parlamentaria, no procedería la inconstitucionalidad y nulidad de la ley recurrida.

Sin embargo, sentada esta premisa de la que parte el Tribunal Constitucional, nuestro comentario de la STC 155/2017 ha de centrarse ahora en la determinación del régimen de emisión del informe una vez que ha sido efectivamente solicitado. En los fundamentos jurídicos 4 y 5, el Tribunal Constitucional parece sentar las bases de su doctrina al respecto con afirmaciones a las que ya hemos aludido. Señala así que la discusión procesal se ha de entender ceñida, además de a si el informe se pidió de una manera regular, a que se hiciera «en términos tales que permitieran a aquella [la comunidad autónoma de Aragón] manifestar con efectividad su criterio al respecto» y que el órgano

25 Así, en el fundamento jurídico 4 se alude a que «la discusión procesal se ha de entender objetivamente ceñida a si el informe se pidió de una manera regular y en términos tales que permitieran a aquella [la comunidad autónoma de Aragón] manifestar con efectividad su criterio al respecto». Y en el fundamento jurídico $7 \mathrm{~b}$ se destaca que las irregularidades cometidas por el Congreso de los Diputados no provocan, por sí solas, la inconstitucionalidad de la ley recurrida, dado que «la mencionada Cámara legislativa, a diferencia de lo planteado en el caso resuelto por la STC 13/2015, no omitió, sin más, la solicitud del informe autonómico, informe que fue efectivamente recabado".

26 En concreto, se alude a la STC 164/2013, en la que tras afirmar en su fundamento jurídico 4 , en la línea antes apuntada, que la ausencia de la solicitud del informe determina la inconstitucionalidad de la norma recurrida, se descarta rotundamente en el fundamento jurídico 5 el argumento de que la publicidad del proceso legislativo habría permitido a la comunidad autónoma conocer la tramitación de las correspondientes normas y emitir el informe que no se le había solicitado. 
del Estado «ha de dar ocasión para que el criterio autonómico pueda ser manifestado y tenido en cuenta en cada fase procedimental relevante antes de que llegue a su término el procedimiento mismo» (la cursiva es nuestra), en cuanto que tiene «el deber de respetar el ejercicio efectivo de esta atribución autonómica».

Pues bien, sobre estas bases generales el Tribunal Constitucional va, de manera expresa o implícita, concretando o precisando su posición en relación con las distintas fases del procedimiento legislativo. Así, no le plantea problema alguno ${ }^{27}$ el que la ponencia en el Congreso de los Diputados realizara su labor y acordara la aceptación de las enmiendas consideradas sin el informe autonómico, respecto del cual, no obstante, acordó que se solicitara. Por el contrario, en el fundamento jurídico 7 a va a considerar que merece reproche la actuación del Congreso de los Diputados al no permitir la emisión del informe autonómico con anterioridad a la celebración de la sesión de la Comisión en la que se aprobó con competencia legislativa plena el proyecto de ley ${ }^{28}$.

De esta manera, puede concluirse ya que el Tribunal Constitucional sostiene que una vez que ha sido aceptada la enmienda por un órgano parlamentario, no antes, surge la obligación de solicitar el informe autonómico y que, a partir de ese momento, ha de darse oportunidad de que todas las actuaciones de relevancia que se realicen para la tramitación legislativa cuenten ya con el informe emitido.

Sin embargo, inmediatamente el Tribunal Constitucional afirma ${ }^{29}$ (FJ $7 b)$ que el incumplimiento de esta obligación por el Congreso de los Diputados «no provoca, en sí mismo considerado, la inconstitucionalidad de las disposiciones de ley que en este recurso se pretende». Para ello sería preciso que,

[...] atendida la tramitación desenvuelta en las Cortes Generales y las demás circunstancias relevantes, la atribución que establece el artículo 72.3 EAAr hubiera sido de imposible ejercicio o defensa por parte de las instituciones autonómicas, pues bien claro está que un vicio de procedimiento como el que aquí

27 Literalmente, esto es, el Tribunal Constitucional no dedica una sola línea al análisis de la cuestión, a pesar de que, como expusimos, había sido desarrollada, con posturas opuestas, por las representaciones procesales del recurrente y del Congreso de los Diputados.

28 En efecto, dicha sesión tuvo lugar el día 13 de mayo de 2015, mientras que la solicitud del informe fue recibida por la comunidad autónoma el día 19 de mayo.

29 «Sorprendentemente», señala, en el número 112 de esta misma revista (enero/abril 2018), De la Quadra-Salcedo Janini, quien, por lo demás, se muestra crítico con la decisión de la STC 155/2017 (pp. 266-267). 
hemos constatado no habría de afectar finalmente a la ley, viciándola a su vez, si la participación de la Comunidad Autónoma prevista en aquella disposición del Estatuto hubiera podido, pese a todo, ser ejercida o, cuando menos invocada ante las Cámaras con alguna posible eficacia, de haberlo intentado así los correspondientes órganos de la Comunidad Autónoma.

He aquí la declaración general sobre la que el Tribunal Constitucional parece querer construir el fundamento de la decisión a adoptar. Por todo ello, el Tribunal Constitucional concluye que a pesar de que la comunidad autónoma de Aragón fue requerida para emitir su informe, no lo llegó a evacuar ante el Senado, pudiéndolo haber hecho, ni invocó ante las Cortes Generales el menoscabo de la atribución propia, que podía acaso haberse reparado en el procedimiento legislativo. Añade que el art. 72.3 del Estatuto de Autonomía de Aragón

[...] compromete a los titulares de este derecho de participación en orden a poner el debido celo en su ejercicio o a denunciar, llegado el caso, su merma en el curso del procedimiento en el que se padeció tal menoscabo. Si lo primero no se realizó, la ley, desde luego, no nació viciada y así es de entender ahora. Tampoco podría esperarse conclusión diferente, por lo demás, cuando no se reaccionó oportunamente frente a un proceder que, sin protesta previa alguna, se trae ante esta jurisdicción para solicitar la declaración de constitucionalidad de normas de ley.

Todo ello conduce a la desestimación del recurso de inconstitucionalidad. Al inicio del fundamento jurídico 8 el Tribunal Constitucional parece resumir el argumento esencial de esa decisión en la línea que hemos expuesto: «El Tribunal no aprecia que, a lo largo de la tramitación en las Cortes Generales de las enmiendas controvertidas, la Comunidad Autónoma se hubiera visto privada, en todo momento y en términos absolutos, de la posibilidad de ejercer o, en su defecto, de hacer valer la atribución estatutaria».

\section{POSICIÓN QUE SE MANTIENE}

Es indudable que ya, al hilo de los aspectos que hemos ido tratando, se han realizado diversas consideraciones o apuntes sobre nuestro criterio en relación con las cuestiones planteadas en la STC 155/2017 y sobre los pronunciamientos que en ella se contienen. No obstante, ha llegado el momento de exponer de manera directa y ordenada nuestra postura o posición al respecto. 
1) El art. 72.3 del Estatuto de Autonomía de Aragón exige un informe de la comunidad autónoma para cualquier propuesta de obra hidráulica o de transferencia de aguas que afecte a su territorio. Podría pensarse, por tanto y en principio, que tal informe siempre debe existir, de modo que, con independencia de que el informe haya de emitirse antes o después de la propuesta, esta no podría ser definitivamente aceptada o aprobada, en ningún caso, si no se ha emitido el considerado informe.

Sin embargo, es claro también que esta solución no puede ser aceptada. Existen otros valores o intereses relevantes en presencia que justifican sobradamente negar esa exigencia insoslayable del informe autonómico. Fundamentalmente, desde luego, que el ejercicio de sus competencias por otros entes u órganos no puede quedar absolutamente condicionado por la circunstancia de que el órgano autonómico, por unas u otras razones, no emita el preceptivo informe ${ }^{30}$. Por ello, no solo es perfectamente posible, ni tampoco solo deseable, sino que viene rigurosamente exigido por los intereses públicos en presencia, el que se regule procedimentalmente la emisión del informe. Ello, lógicamente, comprende muy diversos aspectos, como puede ser el momento concreto de la solicitud del informe o quién debe solicitarlo o emitirlo, pero, esencialmente, se refiere al plazo o, mejor aún, a los elementos temporales del informe.

En supuestos como el que nos ocupa, informes autonómicos que se insertan en un procedimiento estatal, el Tribunal Constitucional ha establecido con toda claridad que la competencia para la regulación de ese procedimiento para la emisión del informe corresponde al Estado ${ }^{31}$. Debe aclararse, no obstante, que esa regulación procedimental del informe, aunque es evidente que tiene unos muy amplios márgenes

30 Coincidimos así con lo que manifiesta la STC 155/2017 (FJ 5b) en el sentido de que si el «parecer autonómico hubiera sido oportuna y regularmente recabado y si la Comunidad Autónoma, en hipótesis, hubiera omitido la manifestación de su criterio en el plazo al efecto fijado, no por ello la prosecución del trámite legislativo sin ese informe determinaría que la ley finalmente aprobada hubiera nacido viciada, siendo inasumible la conclusión contraria, que supondría tanto como conferir a la Comunidad Autónoma un poder de veto ex silentio frente al ejercicio de la potestad legislativa del Estado sobre ámbitos de su exclusiva competencia».

31 Con la reserva, como señala la STC 155/2017, de dejar siempre a salvo la exclusiva competencia de la comunidad autónoma en punto a la ordenación de sus instituciones de autogobierno. En cualquier caso, la cuestión que nos ocupa se ha tratado in extenso en el apartado IV de este comentario. 
para su concreción, también debe respetar unas elementales exigencias. Fundamentalmente, que permita que la comunidad autónoma pueda emitir su informe en condiciones tales que pueda resultar adecuado para su finalidad, esto es, servir al Estado para adoptar una decisión definitiva más correcta y adecuada.

Ahora bien, lo que sí es lógico corolario de lo que venimos exponiendo es que en caso de que no se haya regulado procedimentalmente la emisión del informe autonómico, desatendiendo así el Estado la carga que sobre él recae para permitir el adecuado ejercicio de su competencia, no puede imputarse a la comunidad autónoma ninguna falta de diligencia relevante en la emisión del informe. Y ello no solo por la consideración de que la razón de ser de la intervención de la comunidad autónoma en el procedimiento estatal no es la defensa sin más de los intereses autonómicos, sino la exposición de cuál es la decisión más adecuada previa valoración de todos los intereses en presencia, y teniendo en cuenta, eso sí, que se considera que la comunidad autónoma es la instancia que más adecuadamente puede apreciar, conocer y valorar los intereses autonómicos. También, desde luego, porque ante la ausencia, imputable al Estado, de unas normas procedimentales mínimas que garanticen a la comunidad autónoma el conocimiento de las circunstancias concretas en las que ha de emitir su informe, con la consecuente garantía de la seguridad jurídica, esencial en aspectos de la máxima relevancia como el que nos ocupa, es al Estado al que va a corresponder suplir esa ausencia de regulación general, indicando a la comunidad autónoma los aspectos esenciales (sin duda, fundamentalmente los temporales) para la emisión de su informe. Naturalmente, esta fijación estatal ad casum de los elementos esenciales para la emisión del informe debe respetar, por un lado, las mismas exigencias anteriormente expuestas relativas a posibilitar que el informe autonómico pueda cumplir su específica finalidad y, por otro lado, las exigencias que en cada caso vengan establecidas por la general normativa de aplicación respecto de la competencia y forma para establecer dichos elementos y respecto del contenido y de las condiciones posibles de esos elementos a fijar o establecer.

Pero, desde luego, lo que en ningún caso puede ocurrir, porque ello sería tanto como ignorar el reseñado y esencial principio de seguridad jurídica, es que la determinación de si la comunidad autónoma se ha visto o no privada de forma irregular de la posibilidad de emitir su informe, con las correspondientes consecuencias, sean estas cuales 
sean en cada caso, se haga depender de un posterior y siempre inseguro análisis de las circunstancias concurrentes en cada supuesto, tendente a determinar si la comunidad autónoma actuó o no con la debida o suficiente diligencia o el grado de intensidad de esa diligencia exigible. Máxime en casos como el que nos ocupa, en que de la decisión que se adopte sobre estos aspectos puede depender, nada más y nada menos, la declaración de inconstitucionalidad y nulidad de una disposición con rango de ley y, más aún, que en caso de que se estime que la omisión del informe no es relevante, que permanezca en el ordenamiento jurídico una disposición con rango de ley cuyo contenido, acaso, hubiera sido otro de haberse emitido adecuadamente el informe autonómico.

Pues bien, el análisis de la STC 155/2017 permite concluir que se han desconocido estos criterios generales que hemos expuesto. En efecto, llama la atención, ante todo, que en la sentencia no se dedica atención alguna, ni por tanto se extraen consecuencias de ella, a la circunstancia de que no existía una regulación procedimental, por parte de las Cortes Generales, sobre la emisión del informe y, muy especialmente, sobre el plazo de que disponía la comunidad autónoma para emitirlo o, más concretamente aún, sobre los elementos temporales de relevancia para dicha emisión (momento en el que debía solicitarse el informe, plazo para emitirlo o momento antes del cual resulta necesaria su emisión, etc. $)^{32}$.

32 Curiosamente, sin embargo, en el fundamento jurídico 5b, como ya hemos señalado, casi en la exposición inicial de las consideraciones generales sobre el art. 72.3 del Estatuto de Autonomía de Aragón, la sentencia alude, como elemento esencial para la irrelevancia de la omisión del informe respecto de la invalidez de las disposiciones impugnadas, a que la comunidad autónoma «hubiera omitido la manifestación de su criterio en el plazo al efecto fijado» (la cursiva es nuestra).

En ningún momento posterior de la sentencia, sorprendentemente, se va a volver a aludir a esa inexistencia de plazo para emitir el informe y, desde luego, vista la solución final adoptada, no va a tener al efecto la más mínima relevancia según el Tribunal Constitucional.

Por el contrario, en su voto particular, el magistrado Conde-Pumpido Tourón sí se refiere en diversas ocasiones a la necesidad de que se fije un plazo para la emisión del informe autonómico. Incluso alude a la necesidad de suspender el procedimiento parlamentario en curso para dar oportunidad al órgano autonómico para emitir su informe o se refiere a que de la sentencia se desprende que, al venir a configurar un informe que solo necesita ser solicitado pero no esperado, deja totalmente en manos de quien lo pide la decisión de fijar o no un plazo razonable para su emisión. 
Así, en ningún momento se fijó, ni en consecuencia el órgano autonómico que resultara competente, cualquiera que fuera, pudo conocerlo, un plazo para la emisión del informe. Más bien todo lo contrario; tanto el Congreso de los Diputados como el Senado prosiguieron su actividad legislativa al ritmo que pudiéramos denominar normal, esto es, sin consideración alguna a la circunstancia de que era precisa la emisión del informe autonómico para la decisión final que iban a adoptar. Ello es particularmente evidente respecto de la actuación inicial del Congreso

En este sentido, no obstante, interesa destacar que cita el magistrado discrepante en su apoyo dos sentencias del Tribunal de Justicia, de 29 de octubre de 1980 y de 30 de marzo de 1995. De lo que expone parece que quiere desprender de esas sentencias (referidas a la exigencia de participación del Parlamento Europeo en el proceso legislativo comunitario) la necesidad de que el dictamen no solo sea solicitado, sino también efectivamente emitido. Sin embargo, en la segunda de las sentencias citadas el dictamen del Parlamento Europeo, a pesar de ser solicitado por el Consejo, no se emitió y, no obstante, el Tribunal de Justicia concluyó que era irrelevante tal omisión, habida cuenta de que el incumplimiento de la formalidad sustancial que constituía la consulta se debió, a su vez, al incumplimiento por parte del Parlamento Europeo de su deber de cooperación leal frente al Consejo, de modo que el Parlamento Europeo no podía censurar válidamente al Consejo por no haber esperado su dictamen para adoptar el reglamento impugnado.

Como se aprecia, y con independencia de su correcta aplicación a las circunstancias del caso concreto, parece que existe una sustancial coincidencia entre la doctrina general de la sentencia del Tribunal de Justicia que acabamos de considerar y la de la STC 155/2017, esto es, que la falta de actitud diligente del órgano que ha de emitir el informe sí que tiene relevancia para la decisión a adoptar en los casos de omisión del informe. Otra cosa es que se considere que para que esa falta de diligencia tenga relevancia es preciso que vaya acompañada de otros factores (como, por ejemplo y en concreto, puede ser que el órgano que ha solicitado el dictamen haya, a su vez, extremado su diligencia y hecho valer todas las posibilidades existentes para obtener la emisión del informe) y que, en ese sentido, sí que existan, a su vez, diferencias sustanciales entre ambas sentencias consideradas. Pero parece que poner de relieve estas diferencias hubiera exigido un mayor esfuerzo argumentativo por parte del magistrado discrepante. Máxime cuando a continuación este acusa a la STC 155/2017, como hemos seńalado, de haber «inventado una nueva categoría de informe, el informe que únicamente requiere ser solicitado pero que no necesita ser esperado, esto es, el informe al que, de entrada y con plena libertad, se le puede negar cualquier posible influencia, pues quedaría totalmente en manos de quien lo pide la decisión de fijar o no un plazo razonable para su emisión y la decisión de esperar o no a que se pronuncie la entidad requerida». La acusación parece, cuando menos, exagerada. No es eso, desde luego, lo que dice la sentencia, en ningún lugar de ella. 
de los Diputados; no otra cosa puede desprenderse de la circunstancia de que la solicitud de informe se remitió a la comunidad autónoma de Aragón el día 12 de mayo de 2015 y se recibió por aquella el día 19 de mayo, mientras que el día 13 de mayo la Comisión competente del Congreso de los Diputados procedía a la aprobación, con competencia legislativa plena, del proyecto de ley ${ }^{33}$. Pero también en las sucesivas fases del procedimiento legislativo es claro que ninguna incidencia tuvo la circunstancia de que se hallaba pendiente de emisión un informe preceptivo $^{34}$.

2) A nuestro juicio, las consideraciones que hemos expuesto hasta este momento son absolutamente decisivas para la solución del supuesto planteado, en concreto, para la determinación de si se ha producido la que reiteradamente venimos denominando irregular omisión del informe preceptivo autonómico.

En efecto, a quien correspondía la regulación procedimental de la emisión del informe preceptivo desatendió por completo su establecimiento con carácter previo y general, lo que ya suponía una merma esencial de las exigencias de predeterminación normativa y garantía de certidumbre en la actuación que va a exigirse a terceros que están en la base misma del esencial principio de seguridad jurídica. Pero ni siquiera las concretas actuaciones que las Cortes Generales realizan al hilo de la tramitación del específico procedimiento que están desarrollando permiten, en modo alguno, ofrecer a la comunidad autónoma unas mínimas dosis de esa exigible certidumbre en su actuación, máxime cuando afecta a un aspecto de tanta relevancia como es la emisión de un informe que está expresa y específicamente previsto en el Estatuto de Autonomía de Aragón.

33 Esta evidente ignorancia por el Congreso de los Diputados, en su actuación, de la circunstancia de que era necesaria la emisión del informe autonómico fue, además, deliberada, como lo prueba el que, en el debate, el presidente de la Comisión, preguntado por el Grupo Parlamentario Socialista acerca de si se había recibido el informe, manifestó que no existía constancia de ello.

34 A pesar de que en el Senado se presentaron enmiendas justificadas en la ausencia del preceptivo informe autonómico y de que en el debate en Comisión se denunció la inexistencia de este; asimismo, en el Pleno se rechazaron los correspondientes votos particulares y en el debate se aludió a la ausencia del preceptivo informe.

Por su parte, en el debate final en el Pleno del Congreso de los Diputados se volvió a recordar que no se había emitido el correspondiente informe. 
Así, la ponencia del Congreso de los Diputados, una vez aceptadas las correspondientes enmiendas, acordó solicitar el informe preceptivo previsto en el art. 72.3 del Estatuto de Autonomía de Aragón. Como se ha expuesto, a pesar de ello, a pesar de que las Cortes Generales eran conscientes de que, conforme al Estatuto de Autonomía de Aragón, no podían adoptar su decisión definitiva sin contar con el informe de la comunidad autónoma de Aragón, ni comunicaron a esta la más mínima condición, temporal o de cualquier otra especie, a la que debía atenerse para emitir su informe, ni modificaron en lo más mínimo su manera de actuación en la tramitación del procedimiento legislativo para adaptarlo o adecuarlo a esa exigencia del informe de la que eran plenamente conocedoras, ni volvieron a realizar, ni a intentarlo, actuación alguna tendente a procurar que la comunidad autónoma emitiera efectivamente su informe o, al menos, expusiera las razones por las que no lo había emitido y cuáles eran sus previsiones al efecto.

Por ello, frente a esa total y absoluta desatención de las Cortes Generales, específicas garantes de la adecuada tramitación del procedimiento legislativo en el que era exigible el trascendente informe autonómico, carece en principio por completo de relevancia cualquier actuación que haya desarrollado la comunidad autónoma que no haya contribuido a facilitar la emisión de ese informe. Tan solo es imaginable que pueda dotarse de relevancia al deliberado propósito de la comunidad autónoma de no emitir el informe, bien porque no deseaba emitirlo, bien porque, conocedora de que se estaba tramitando el procedimiento legislativo, ha pretendido con la omisión deliberada de su informe cuestionar la validez de la decisión estatal final adoptada en ese procedimiento legislativo.

En realidad, en el primero de los supuestos que acabamos de exponer, esto es, que la comunidad autónoma no deseaba emitir el informe, la carencia de relevancia de su omisión va a ser consecuencia de que la ausencia del informe, que en ningún caso se iba a emitir por la comunidad autónoma, no ha determinado por ello una alteración sustancial o una afectación esencial del proceso de formación de la voluntad parlamentaria. En el segundo de los supuestos expuestos, esto es, una provocación de la inconstitucionalidad y nulidad de la disposición legal mediante la falta de emisión del informe preceptivo, la vulneración del principio de lealtad institucional tendría, sin duda, tal intensidad que vendría a absorber cualquier vicio o defecto, por sustancial que fuera, que las Cortes Generales hubieran cometido en la regulación o concreta tramitación del procedimiento legislativo. 
3) Como hemos expuesto, la entidad de los vicios concurrentes en la actuación de las Cortes Generales va a determinar por sí sola que, a nuestro juicio, se produjo una irregular omisión del informe autonómico preceptivo. Sin embargo, no está de más analizar con detalle las esenciales características de la actuación de la comunidad autónoma. Los reproches que el Tribunal Constitucional dirige a las instituciones autonómicas son esencialmente los que siguen:

a) El Gobierno autonómico no interesó con prontitud el señalamiento de un plazo para informar. Tampoco remitió de inmediato al Senado el informe, una vez que fue pública la aprobación inicial del proyecto por el Congreso de los Diputados ${ }^{35}$, a pesar de que había hecho constar ante la Diputación Permanente de las Cortes de Aragón que ya se estaba preparando ${ }^{36}$.

Tampoco formuló al Senado ninguna otra solicitud o protesta, en concreto, solicitar la ampliación de los plazos del procedimiento legislativo hasta los dos meses que establece el art. 90.2 de la Constitución, o bien invocar la indebida aprobación de las enmiendas en el Congreso de los Diputados sin dar ocasión a la emisión del informe.

A juicio del Tribunal Constitucional, a través de cualquiera de estas actuaciones, el Gobierno autonómico hubiera ofrecido al Senado unos medios adicionales que, quizá, le hubieran hecho cambiar su decisión de aprobar el proyecto de ley con la inclusión de las disposiciones ahora impugnadas ante el Tribunal Constitucional ${ }^{37}$.

35 Curiosamente, aquí el Tribunal Constitucional sí que da relevancia a la publicidad de los trabajos parlamentarios, algo que, como hemos examinado, y con apoyo en pronunciamientos anteriores, niega con rotundidad en el resto de la sentencia.

Pero no destaca el Tribunal Constitucional que en esa comparecencia del Gobierno autonómico ante la Diputación Permanente de las Cortes de Aragón se expuso por el consejero competente no solo que se estaba esperando a que el Congreso de los Diputados pidiera el informe, sino también a «que el Congreso nos diga qué plazo tenemos y en qué condiciones».

37 Naturalmente, respecto de lo que hubiera ocurrido en caso de existencia del informe, nos movemos en el terreno de las suposiciones. Pero interesa muy mucho retener esta idea que el Tribunal Constitucional apunta al hilo de esta concreta cuestión que ahora está analizando, pero que de acuerdo con las consideraciones que nosotros mantenemos tiene una importancia radical. En efecto, el Tribunal Constitucional reconoce expresamente que de haberse emitido el informe otro hubiera podido ser el 
Pues bien, lo cierto es que de todas estas consideraciones del Tribunal Constitucional se desprende, y en este sentido coincidimos plenamente al respecto, que el Gobierno de Aragón podría haber realizado actuaciones que hubieran podido facilitar la emisión del informe. Incluso, no cabe descartar que hubiera podido emitir efectivamente el informe. Mucho más dudoso es definir si el que el Gobierno de Aragón no realizara esas actuaciones revela una falta de la diligencia que normalmente cabe esperar o, por el contrario, que el haberlas realizado hubiera revelado una especial diligencia, normalmente no esperada, en su actuación ${ }^{38}$. No es relevante, sin embargo, a nuestro juicio, tal cuestión. Porque lo que resulta meridianamente claro es que no existen el más mínimo dato o circunstancia de los que se pueda desprender, con la solidez exigible, que el Gobierno de Aragón no deseaba emitir el informe o que quiso deliberadamente aprovecharse de la situación existente y de las circunstancias concurrentes para, mediante la omisión del informe preceptivo, conseguir la declaración de inconstitucionalidad y nulidad de las disposiciones controvertidas. Y, como ya habíamos adelantado, al no producirse estos supuestos excepcionales, del resto de las circunstancias concurrentes se desprende, a nuestro juicio, que se produjo una irregular omisión del informe autonómico.

b) Una breve incursión hace también el Tribunal Constitucional en la circunstancia de que las Cortes de Aragón no realizaran actuación alguna similar a aquellas cuya omisión reprocha al Gobierno de Aragón. No podemos entrar, por razones de espacio, en el análisis detallado de los más que discutibles y forzados pronunciamientos

sentido de la decisión que, en definitiva, se adoptara por las Cortes Generales. Dicho en los términos de su doctrina a los que nos hemos referido anteriormente, el Tribunal Constitucional reconoce expresamente que la falta de emisión del informe era susceptible de producir una alteración sustancial o afectar esencialmente al proceso de formación de la voluntad de las Cámaras.

Ciertamente, creemos que quienes conocen los modos de actuación de instituciones como las que estamos considerando coincidirán en que cuando se trata de la tramitación de procedimientos tan específicos como el que nos ocupa, un procedimiento legislativo, con sus diversas fases ante las dos Cámaras, su intervención o participación solo se produce normalmente cuando son requeridos formalmente para ello, siendo absolutamente excepcional el que, espontáneamente, y sin existencia de un cauce normativo específico que les habilite, realicen actuaciones o formulen solicitudes o protestas en el mismo. 
que al respecto realiza el Tribunal. Baste con reiterar las consideraciones que acabamos de exponer para descartar la irrelevancia de tal circunstancia respecto de la irregular omisión del informe autonómico.

4) Sentado, pues, que a nuestro juicio se produjo lo que hemos denominado irregular omisión del informe preceptivo previsto en el art. 72.3 del Estatuto de Autonomía de Aragón, debemos proceder a examinar, conforme a las consideraciones que con carácter general exponíamos más arriba, si tal irregular omisión tiene suficiente relevancia para determinar la inconstitucionalidad y nulidad de las disposiciones impugnadas, por haber podido suponer una alteración sustancial o una afectación esencial del proceso de formación de la voluntad parlamentaria ${ }^{39}$.

La respuesta positiva a esa cuestión es contundente. Bastaría quizá para afirmarlo así la circunstancia de que, según se desprende de los antecedentes y fundamentos jurídicos de la STC 155/2017, ninguna de las partes que ha defendido la desestimación del recurso de inconstitucionalidad ha pretendido siquiera sostener que, aunque se hubiera emitido el informe, la decisión parlamentaria final hubiera sido la misma, cuando la carga de la prueba le correspondería, en su caso, a tales partes. Pero, sobre todo, no existe dato alguno del que pueda desprenderse lógicamente la conclusión de que habría concurrido tal circunstancia, esto es, que aunque se hubiera emitido el informe autonómico las disposiciones legales impugnadas habrían sido definitivamente aprobadas en los mismos términos; más aún, es que ni siquiera puede intuirse por qué el informe autonómico, cuyo contenido posible nadie se ha preocupado de exponer o predecir, en ningún caso iba a determinar la alteración de la decisión legislativa final. Recuérdese, por lo demás, que el propio Tribunal Constitucional, incidentalmente, reconoce que si se hubiera emitido el informe autonómico la decisión legislativa podría acaso haber sido distinta.

5) De este modo, por todo lo expuesto, reiteramos nuestra conclusión en el sentido de que el recurso de inconstitucionalidad debió ser estimado y, en consecuencia, las disposiciones legales impugnadas declaradas inconstitucionales y nulas.

39 Naturalmente, no podemos entrar ahora en la cuestión, de sumo interés en cualquier caso, de si el Tribunal Constitucional podía volver a realizar una declaración de nulidad diferida, valorando otra vez todas las circunstancias concurrentes en el supuesto. 
Pero no podemos terminar nuestro comentario de la STC 155/2017 sin hacer referencia a una circunstancia de indudable interés, que curiosamente apunta la propia sentencia, pero sin extraer mayores conclusiones de ella, lo que, a su vez, motiva la crítica del magistrado Conde-Pumpido Tourón en su voto particular.

En efecto, en el fundamento jurídico $5 \mathrm{c}$ de la sentencia, el Tribunal Constitucional señala que la irregular omisión del informe preceptivo autonómico podrá lesionar no solo la atribución de que goza la comunidad autónoma de Aragón conforme al art. 72.3 del Estatuto de Autonomía de Aragón, sino, además, eventualmente, «los derechos de los parlamentarios que, al amparo de lo prevenido en el artículo 23.1 CE, hubieran reclamado sin éxito de aquellos órganos [los órganos de gobierno de las Cámaras], la oportuna apertura del trámite informativo, al experimentar, tanto ellos como las propias Cámaras, una ilegítima privación de un elemento de juicio necesario para su decisión».

A nuestro juicio, la observación del Tribunal Constitucional, importante sin duda desde un punto de vista teórico ${ }^{40}$, no tiene mayor trascenden-

40 Aunque llena de imprecisiones, como la relativa, por ejemplo, a que parece que solo se prevé el supuesto de falta de solicitud del informe («si la misma, pese a ello, no se interesara regularmente por los órganos de gobierno de las Cámaras»), o la referida a que se alude a que si los parlamentarios reclamaron la oportuna apertura del trámite informativo lo estarían haciendo al amparo del art. 23.1 de la Constitución (muy discutible con arreglo a la actual doctrina del Tribunal Constitucional es la pertinencia de aludir directamente y sin más al apdo. 1 de ese art. 23 de la Constitución, sin referencia alguna a su apdo. 2), cuando es claro que el fundamento de su solicitud se encontraría precisamente en el art. 72.3 del Estatuto de Autonomía de Aragón, sin perjuicio de que su indebida negación supusiera una vulneración del art. 23 de la Constitución y de los derechos fundamentales en él reconocidos. Y precisamente en línea con lo que acabamos de exponer se encuentra el principal reproche que cabe hacer a esta observación imprecisa del Tribunal Constitucional. En efecto, el Tribunal Constitucional se refiere a la posible lesión de los derechos fundamentales reconocidos en el art. 23 de la Constitución de determinados parlamentarios afectados, cuando en realidad lo que en el supuesto de irregular omisión del informe preceptivo vendría a producirse es la vulneración del art. 23 de la Constitución, hubieran sido o no alegados y hechos valer por los parlamentarios afectados los derechos fundamentales que proclama. En otras palabras, es preciso distinguir, y el Tribunal Constitucional no solo no lo hace sino que confunde, entre la vulneración de la norma de derecho fundamental y la efectiva vulneración de los derechos fundamentales reconocidos en ella de determinadas personas o, si se prefiere, distinguir la vertiente objetiva y la vertiente subjetiva del derecho fundamental y, a partir de ahí, determinar si ha existido lesión de ambas o no y la trascendencia que ello puede tener para la 
cia práctica que la de servir para confirmar que la omisión de un informe de las características del que nos ocupa, susceptible incluso de afectar al art. 23 de la Constitución y a los derechos fundamentales en él reconocidos, tiene tal relevancia que se justifican sobradamente las consideraciones de carácter general que hemos expuesto referidas a que se debe partir de que esa omisión determina la inconstitucionalidad y nulidad de las disposiciones a las que afecte.

Por lo demás, no puede dejar de destacarse que, quizá, esta imprecisa observación del Tribunal Constitucional (que, repetimos, por lo demás puede considerarse oportuna, dada la imbricación con la cuestión planteada del art. 23 de la Constitución y de los derechos fundamentales en él reconocidos) viene motivada por la circunstancia de que muy poco antes de la STC 155/2017 el Tribunal Constitucional había dictado la STC 114/2017, de 17 de octubre, y la STC 124/2017, de 8 de noviembre, en las que, en dos recursos de inconstitucionalidad cuya trascendencia no necesita ser justificada ${ }^{41}$, se realiza un examen de la relevancia de la omisión en un procedimiento legislativo de un informe previsto en un estatuto de autonomía ${ }^{42}$, en el que ya se apunta la incidencia de la cuestión sobre los derechos fundamentales reconocidos en el art. 23 de la Constitución ${ }^{43}$. Y, además, muy probablemente influyó también el que el Tribunal Constitucional estuviera en el mismo momento temporal trabajando en los recursos de amparo que serían resueltos por la STC 10/2018, de 5 de febrero, y por la STC 27/2018, de 5 de marzo, en cuyos respectivos fundamentos jurídicos cuartos se destaca ya expresamente la directa relación en supuestos como el que nos ocupa entre los vicios de procedimiento como causa de inconstitucionalidad de la norma $y$, de forma específica, como eventuales vulneraciones de derechos o facultades atribuidos a los parlamentarios, en concreto, los reconocidos en el art. 23 de la Constitución.

solución del supuesto planteado. Sobre el tema, es esencial Jiménez Campo (1999: 31 y ss.).

41 Resolvían, respectivamente, los recursos de inconstitucionalidad interpuestos contra la Ley del Parlamento de Cataluña 19/2017, de 6 de septiembre, denominada «del referéndum de autodeterminación", y contra la Ley del Parlamento de Cataluña 20/2017, de 8 de septiembre, denominada de «transitoriedad jurídica y fundacional de la República».

42 En concreto, el dictamen del Consejo de Garantías Estatutarias previsto en el Estatuto de Autonomía de Cataluña.

43 Vide el fundamento jurídico 6d de la STC 114/2017 y el fundamento jurídico 6c de la STC 124/2017. 


\section{Bibliografía}

Bassols Coma, M. (2008). La gestión del agua y la reforma de los estatutos de autonomía. Especial referencia a los trasvases intercuencas. En A. Fanlo Loras (dir.). La ordenación jurídica del Trasvase Tajo-Segura (pp. 363-392). Murcia: Instituto Euromediterráneo del Agua.

Biglino Campos, P. (1991). Los vicios en el procedimiento legislativo. Madrid: Centro de Estudios Constitucionales.

Castro Marquina, G. (2016). Una breve historia del Estatuto de Autonomía de Aragón en materia de aguas. Revista Aragonesa de Administración Pública, 47-48, 64-116.

Embid Irujo, A. (2007). Los nuevos estatutos de autonomía y el reparto de competencias sobre el agua y las obras hidráulicas entre el Estado y las comunidades autónomas. En A. Embid Irujo (dir.). Agua y territorio (Consideración especial de la reforma de los Estatutos de Autonomía) (pp. 13-80). Cizur Menor (Navarra): Aranzadi.

- (2009). Agua y territorio. Nuevas reflexiones jurídicas. Revista Aragonesa de Administración Pública, número extraordinario 11, 23-69.

Fanlo Loras, A. (2007). La unidad de gestión de las cuencas hidrográficas. Murcia: Instituto Euromediterráneo del Agua.

Fanlo Loras, A. y Garrorena Morales, A. (2008). La constitucionalidad de los nuevos Estatutos en materia de aguas (A propósito de la propuesta de Estatuto de Autonomía de Castilla-La Mancha). Murcia: Instituto Euromediterráneo del Agua.

Favoreu, L. y Rubio Llorente, F. (1991). El bloque de la constitucionalidad (Simposium franco-español de Derecho constitucional). Madrid: Civitas.

Jiménez Asensio, R. (1996). La ley como fuente del Derecho parlamentario. En J. C. da Silva Ochoa (coord.). Instituciones de Derecho Parlamentario, I. Las fuentes del Derecho Parlamentario (pp. 143-215). Vitoria-Gasteiz: Parlamento Vasco.

Jiménez Campo, J. (1999). Derechos fundamentales. Concepto y garantías. Madrid: Trotta.

Martín Cáceres, A. F. (1988). La protección constitucional del régimen económico-fiscal canario (un comentario a la sentencia del Tribunal Constitucional de 13 de marzo de 1984). Revista Española de Derecho Financiero, 59, 451-469.

Mauricio Subirana, S. (1994). La franquicia sobre el consumo en Canarias. Análisis histórico y régimen actual. Madrid: Instituto Canario de Administración Pública; Marcial Pons.

Moreno Fernández, J. I. (2018). Disposición adicional tercera. En M. E. Casas Baamonde y M. Rodríguez-Piñero y Bravo-Ferrer (dirs.). Comentarios a la Constitución Española: XL Aniversario. Tomo II (pp. 1932-1942). Las Rozas (Madrid): Fundación Wolters Kluwer; Boletín Oficial del Estado; Tribunal Constitucional; Ministerio de Justicial.

Orozco Muñoz, M. (1997). El régimen fiscal especial de Canarias (su conformación por el bloque de la constitucionalidad). Madrid: Cabildo de Tenerife; Marcial Pons.

Pascua Mateo, F. (2014). Fuentes y control del Derecho Parlamentario y de la Administración parlamentaria. Madrid: Tribunal Constitucional; Centro de Estudios Políticos y Constitucionales. 